\title{
Aorto-oesophageal fistula post-thoracic endovascular repair of type B aortic dissection: an uncommon catastrophic complication
}

\author{
Amit Ajit Deshpande (ㄷ), Rishabh Khurana 다, Manish Shaw, Sanjeev Kumar
}

Cardiovascular Radiology \& Endovascular Interventions, All India Institute of Medical Sciences, New Delhi, India

\section{Correspondence to} Dr Sanjeev Kumar; sanjeevradio@gmail.com

Accepted 12 August 2021
D) Check for updates

(c) BMJ Publishing Group Limited 2021. No commercial re-use. See rights and permissions. Published by BMJ.

\begin{tabular}{l}
\hline To cite: Deshpande AA, \\
Khurana R, Shaw M, \\
et al. BMJ Case Rep \\
2021;14:e243379. \\
doi:10.1136/bcr-2021- \\
243379 \\
\hline
\end{tabular}

\section{DESCRIPTION}

A 79-year-old hypertensive man with chronic type $\mathrm{B}$ aortic dissection (TBAD) came with acute chest pain. CT revealed partially thrombosed aneurysmal dilatation of false lumen, compressing trachea and oesophagus (chronic complicated TBAD) with the extremely tortuous descending thoracic aorta (figures $1 \mathrm{~A}$ and $2 \mathrm{~A}$, video 1). An urgent thoracic endovascular repair (TEVAR) was done. Two overlapping stent grafts were deployed starting in proximal landing zone 2 and up to the coeliac artery ostium distally.

The procedure was uneventful, however, he developed fever a month later without haematemesis.

$\mathrm{He}$ had raised total leucocyte count. CT showed patent stent graft (figure 1B) with a rent (figure $2 \mathrm{~B}$ ) in the wall of the oesophagus, peripherally enhancing thrombosed pseudoaneurysm and pleural effusion (figure 2B) suggestive of aortooesophageal fistula (AEF) with perigraft infection (video 2). The radical surgery was ruled out due to multiple comorbidities and the patient refused a palliative oesophageal stenting. The grave prognosis was explained to the patient. He was put on feeding jejunostomy with broad-spectrum antiobiotics, however, he succumbed to the infection a month later.

Secondary AEF is an uncommon (1.5\%-1.9\%) catastrophic complication of the TEVAR. ${ }^{1}{ }^{2}$ It can occur either due to pressure erosion of the oesophagus secondary to progressive forces of selfexpanding endograft or infection causing erosion of the oesophagus. As perigraft infection and AEF have a reciprocal cause and effect relationship, it

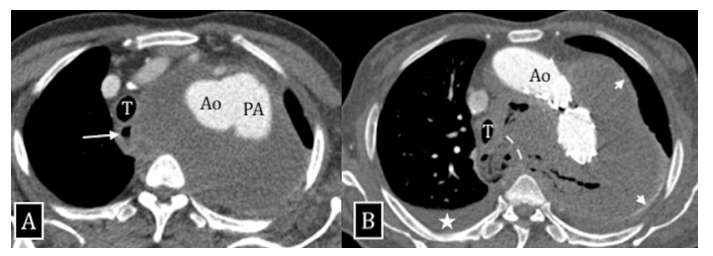

Figure $1 \mathrm{CT}$ axial image at the baseline $(\mathrm{A})$ shows partially thrombosed aneurysmal dilatation of false lumen (marked as PA) of type B aortic dissection compressing on the trachea (marked as T) and oesophagus (arrow). $\mathrm{CT}$ axial image at 1 month (B) postprocedure shows peripherally enhancing thrombosed false lumen (arrowheads), rent in the medial oesophageal wall (dashed line) with continuous air column communicating with the false lumen. Note the patent endograft without endoleak. (Ao - Aorta). PA, Pseudoaneurysm.

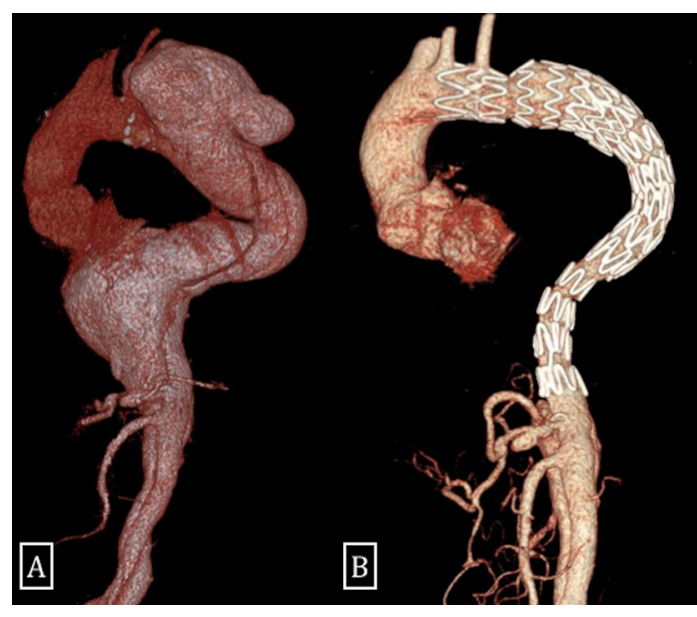

Figure 2 CT volume rendered image at the baseline (A) shows type B aortic dissection with the extremely tortuous descending thoracic aorta. CT volume rendered image at 1 month postprocedure (B) shows patent endograft without evident endoleak.

is difficult to determine the primary cause. The patients usually present with haematemesis (most common), shock or systemic infection. Patients with suspected secondary AEF and inconclusive CT findings should undergo upper gastrointestinal endoscopy. It can reveal a small rent with oozing of blood or an ulcerative lesion. ${ }^{3}$ The radical surgery with oesophagectomy and removal of endograft

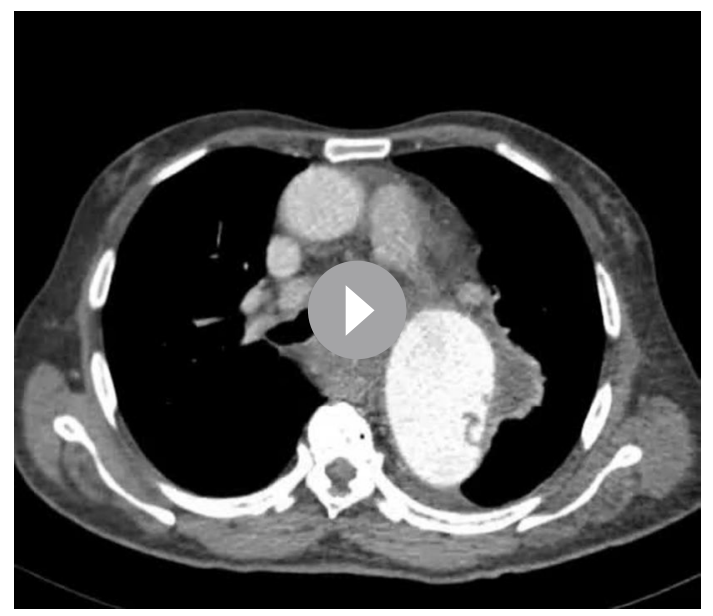

Video 1 CT axial loop shows aneurysmal dilatation of the false lumen of type B aortic dissection compressing oesophagus and trachea. Note is extremely tortuous descending thoracic aorta. 


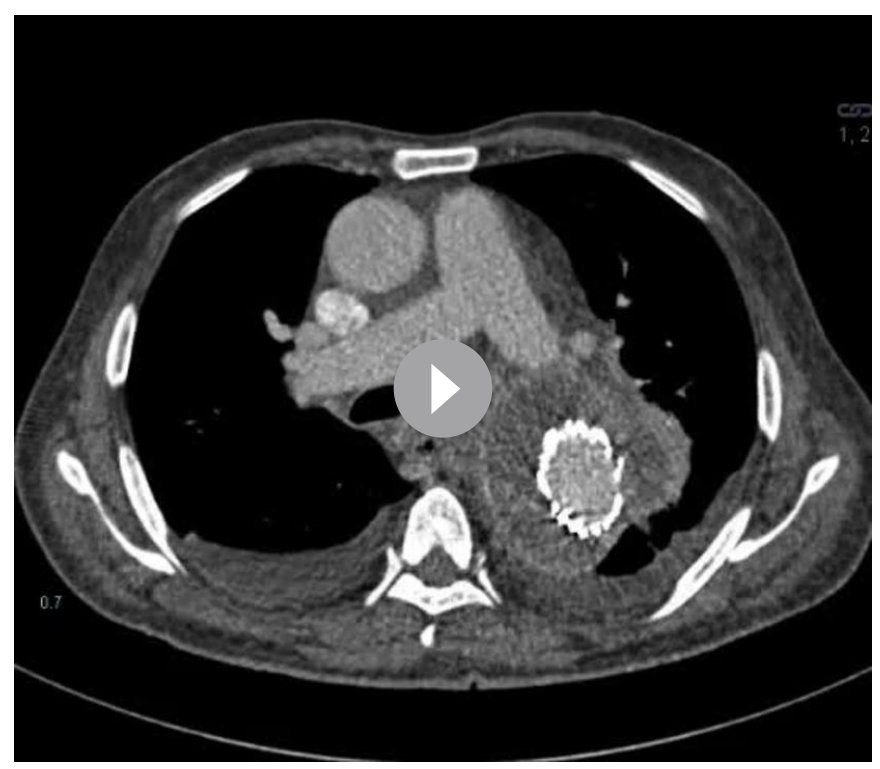

Video 2 CT axial loop shows rent in the medial oesophageal wall, direct continuation of air foci from the oesophagus into the thrombosed false lumen and peripherally enhancing thrombosed false lumen. Note the patent aortic endograft.

with orthotopic aortic reconstruction offer the best possible outcome. Currently, a combination therapy is recommended in patients of secondary AEF presenting with severe hematemesis, comprising of an additional TEVAR to prevent shock with an interval radical surgery. ${ }^{3}$ Although, the exact source of bleeding for haematemesis is not yet established, as all the patients in one of the studies had patent endografts. ${ }^{2}$ The palliative options include a self-expanding metallic stent to cover the rent or a feeding jejunostomy. ${ }^{3} 4$ The patient should be started on antibiotics. There are no specific guidelines regarding the type and duration of antibiotic coverage. But it is ideal to start the antibiotics based on the culture and sensitivity report. In the absence of which, patient can be started on broad-spectrum antibiotics, like the combination of piperacilin-tazobactum and vancomycin. But patient should be monitored carefully, as it can cause nephrotoxicity. ${ }^{5}$ We started the patient on broad-spectrum antibiotic empirically and blood culture was not done. Czerny et $a l^{1}$ noticed the highest 1 -year survival (46\%) after the radical surgery, while there was $100 \%$ mortality after the conservative treatment at 1 year.

\section{Learning points}

- Any patient presenting with fever or haematemesis postendovascular repair of thoracic aorta should undergo thorough evaluation to exclude the possibility of endograft infection or aorto-oesophageal fistula.

- Aorto-oesophageal fistula if detected, should be managed aggressively with radical surgery as early as possible, as it has a high mortality rate.

- Oesophageal stenting and/or feeding jejunostomy can be offered to the surgically unfit candidates; however, it has high 1-year mortality rates.

Contributors AAD and RK: manuscript writing and literature review; MS and SK: manuscript editing and validation.

Funding The authors have not declared a specific grant for this research from any funding agency in the public, commercial or not-for-profit sectors.

Competing interests None declared.

Patient consent for publication Obtained.

Provenance and peer review Not commissioned; externally peer reviewed.

\section{ORCID iDs}

Amit Ajit Deshpande http://orcid.org/0000-0001-7871-5688

Rishabh Khurana http://orcid.org/0000-0002-1268-381X

\section{REFERENCES}

1 Czerny M, Eggebrecht $H$, Sodeck G, et al. New insights regarding the incidence, presentation and treatment options of aorto-oesophageal fistulation after thoracic endovascular aortic repair: the European registry of endovascular aortic repair complications. Eur J Cardiothorac Surg 2014;45:452-7.

2 Eggebrecht H, Mehta RH, Dechene A, et al. Aortoesophageal fistula after thoracic aortic stent-graft placement: a rare but catastrophic complication of a novel emerging technique. JACC Cardiovasc Interv 2009;2:570-6.

3 Uno K, Koike T, Takahashi S, et al. Management of aorto-esophageal fistula secondary after thoracic endovascular aortic repair: a review of literature. Clin J Gastroenterol 2017; 10:393-402

4 Tao M, Shlomovitz E, Darling G, et al. Secondary aorto-esophageal fistula after thoracic aortic aneurysm endovascular repair treated by covered esophageal stenting. World J Clin Cases 2016:4:233-7.

5 Luther MK, Timbrook TT, Caffrey AR, et al. Vancomycin plus piperacillin-tazobactam and acute kidney injury in adults: a systematic review and meta-analysis. Crit Care Med 2018:46:12-20.

Copyright 2021 BMJ Publishing Group. All rights reserved. For permission to reuse any of this content visit

https://www.bmj.com/company/products-services/rights-and-licensing/permissions/

BMJ Case Report Fellows may re-use this article for personal use and teaching without any further permission.

Become a Fellow of BMJ Case Reports today and you can:

- Submit as many cases as you like

- Enjoy fast sympathetic peer review and rapid publication of accepted articles

- Access all the published articles

- Re-use any of the published material for personal use and teaching without further permission

Customer Service

If you have any further queries about your subscription, please contact our customer services team on +44 (0) 2071111105 or via email at support@bmj.com.

Visit casereports.bmj.com for more articles like this and to become a Fellow 